\title{
HbA1c Test as a Tool in the Diagnosis of Gestational Diabetes Mellitus
}

\author{
Paula Breitenbach Renz ${ }^{1}$, Gabriela Cavagnolli ${ }^{1}$, Letícia Schwerz Weinert ${ }^{1,2}$, Sandra \\ Pinho Silveiro ${ }^{1,3}$, Joíza Lins Camargo ${ }^{1,3 *}$
}

1 Graduate Program in Endocrinology, Universidade Federal do Rio Grande do Sul (UFRGS), Porto Alegre, Brazil, 2 School of Medicine, Universidade Católica de Pelotas (UCPEL), Pelotas, Brazil, 3 Endocrinology

Department, Hospital de Clinicas de Porto Alegre (HCPA), Porto Alegre, Brazil

* jcamargo@ @cpa.ufrgs.br

\section{Abstract}

\section{G openaccess}

Citation: Renz PB, Cavagnolli G, Weinert LS, Silveiro SP, Camargo JL (2015) HbA1c Test as a Tool in the Diagnosis of Gestational Diabetes Mellitus. PLOS ONE 10(8): e0135989. doi:10.1371/journal. pone. 0135989

Editor: Bridget Wagner, Broad Institute of Harvard and MIT, UNITED STATES

Received: March 13, 2015

Accepted: July 28, 2015

Published: August 20, 2015

Copyright: @ 2015 Renz et al. This is an open access article distributed under the terms of the Creative Commons Attribution License, which permits unrestricted use, distribution, and reproduction in any medium, provided the original author and source are credited.

Data Availability Statement: All relevant data are within the paper.

Funding: This study was supported by the Research Incentive Fund (FIPE) of the Hospital de Clínicas de Porto Alegre (HCPA). PBR and GC received scholarships from the Coordination for the Enhancement of Higher Level Personnel (CAPES) and the National Council for Scientific and Technological Development (CNPq), respectively.

Competing Interests: The authors have declared that no competing interests exist.

\section{Aims}

Gestational diabetes mellitus (GDM) is a prevalent and potentially serious condition which may put both mothers and neonates at risk. The current recommendation for diagnosis is the oral glucose tolerance test (OGTT). This study aimed to determine the usefulness of $\mathrm{HbA} 1 \mathrm{c}$ test as a diagnostic tool for GDM as compared to the traditional criteria based on the OGTT.

\section{Methods}

This was a diagnostic test accuracy study. We performed OGTT and HbA1c test in women attending prenatal visits at a tertiary hospital. GDM was defined according to WHO1999 or ADA/WHO 2013 criteria. ROC curve was used to evaluate the diagnostic performance of $\mathrm{HbA1c}$. Sensitivity, specificity and likelihood ratios for different $\mathrm{HbA1c}$ cut-off points were calculated.

\section{Results}

Of the 262 women in the third trimester of gestation enrolled in the study, $86(33 \%)$ were diagnosed with GDM. Only five of these women presented $\mathrm{HbA1c} \geq 48 \mathrm{mmol} / \mathrm{mol}(6.5 \%)$. This cut-off point presented $100 \%$ specificity but very low sensitivity (7\%). Based on ROC curve, and considering OGTT as the reference criterion, $\mathrm{HbA1c} \geq 40 \mathrm{mmol} / \mathrm{mol}(5.8 \%)$ showed adequate specificity in diagnosing GDM (94.9\%) but low sensitivity (26.4\%). Unlike, $\mathrm{HbA} 1 \mathrm{c}$ values of $31 \mathrm{mmol} / \mathrm{mol}(5.0 \%)$ presented adequate sensitivity (89.7\%) but low specificity (32.6\%) to detect GDM. For women with $\mathrm{HbA} 1 \mathrm{c} \geq 40 \mathrm{mmol} / \mathrm{mol}(5.8 \%)$, the positive and negative likelihood ratios were $5.14(95 \% \mathrm{Cl} 2.49-10.63)$ and $0.78(0.68-0.88)$, respectively. The post-test probability of GDM was about $40 \%$, representing a 4.0 -fold increase in the mean pre-test probability. This cut-off point could eliminate the need for the unpleasant and laborious OGTT tests in almost one third of cases, as 38\% of patients with GDM may be diagnosable by $\mathrm{HbA} 1 \mathrm{c}$ test alone. 


\section{Conclusions}

Our results show that combined $\mathrm{HbA} 1 \mathrm{c}$ and OGTT measurements may be useful in diagnosing GDM.

\section{Introduction}

Gestational diabetes mellitus (GDM) is a prevalent and potentially serious condition that may lead to adverse effects in both mothers and neonates [1]. It is associated with preeclampsia, increased caesarean rates, and macrosomia $[2,3]$. The detection and treatment of this condition reduce the risks for the mothers as well as for the babies $[4,5]$.

Although the risks of complications in the presence of GDM are well established, there is considerable controversy regarding its diagnosis [6]. Traditionally, the OGTT has been the test of choice for this condition. It can be preceded by a screening strategy such as fasting glycemia (FG) or a glucose load test. However, there are still divergences as to the OGTT cut-offs which should be used for the diagnosis of GDM and also a recent review concluded that the evidence are insufficient to permit assessment of which strategy is best to diagnose GDM [7, 8].

In 2010, the American Diabetes Association (ADA) included HbAlc test as a diagnostic criterion for diabetes (DM) in the general population. The cut-off of $\mathrm{HbAlc} \geq 48 \mathrm{mmol} / \mathrm{mol}$ (6.5\%) was established for the diagnosis, and was endorsed by the World Health Organization (WHO) in 2011 [9, 10]. This cut-off has high specificity in diagnosing DM [11,12,13]. However, HbAlc and glucose tests show very weak agreement, and it seems that these two tests may identify different populations of patients [11].

Recent results from the Hyperglycaemia and Adverse Pregnancy Outcomes (HAPO) study showed that $\mathrm{HbA} 1 \mathrm{c}$ measurements, similar to glycemia levels, were significantly associated with all adverse outcomes, and higher levels of maternal $\mathrm{HbAlc}$ were related to a greater frequency of adverse outcomes [14].

Although OGTT is accepted as the diagnostic test for GDM by international organizations, it requires at least $8 \mathrm{~h}$ fasting, extensive patient preparation, lacks reproducibility, it is time-consuming and unpalatable. Unlike, HbAlc may be measured any time of the day, has less biological variation, higher reproducibility and better analytical stability as compared to glucose measurements [15]. Additionally, $\mathrm{HbAlc}$ test does not need fasting and would be more comfortable for pregnant women than the OGTT. Nevertheless, its use for the diagnosis of GDM has not yet been recommended by any current guidelines.

The aim of this study was to analyse the performance of the HbAlc test in detecting GDM, based on OGTT as the reference test.

\section{Patients and Methods}

This was a study of diagnostic test accuracy to evaluate the performance of the HbAlc test in diagnosing GDM. Our findings were presented according to Standards for Reporting of Diagnostic Accuracy (STARD) initiative guidelines [16] (Fig 1).

Pregnant women in prenatal care, without previous DM, who were referred to the Clinical

Pathology Department of the Hospital de Clinicas de Porto Alegre (HCPA) between September 2009 and July 2012 to perform OGTT tests in the third trimester of pregnancy were consecutively invited to participate in the present study. All women signed an informed consent form and answered a standardized questionnaire. Age, gestational age, obstetric history, smoking, family history of cardiovascular disease (CVD), DM, arterial hypertension (HT), alcohol 


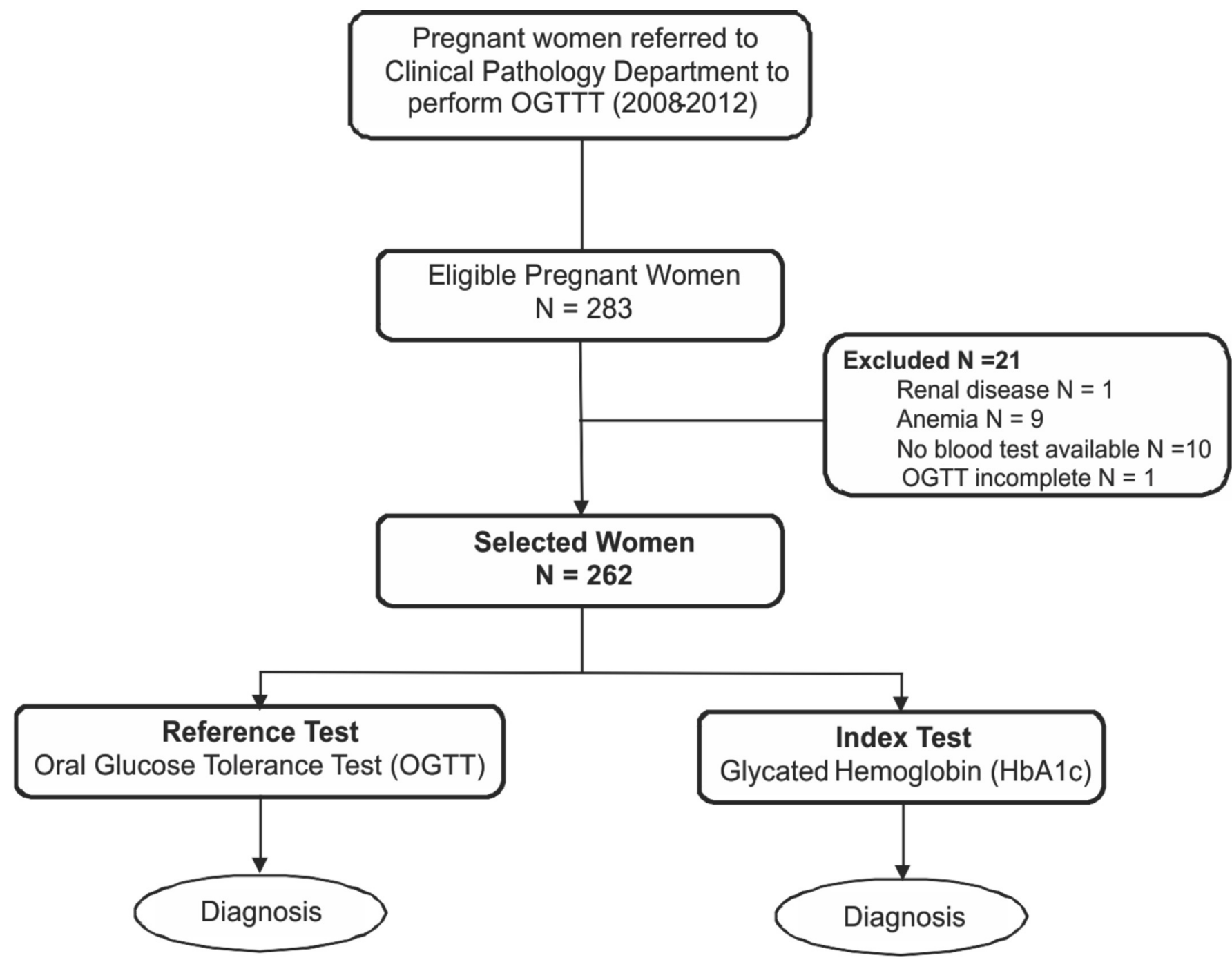

Fig 1. Study Design.

doi:10.1371/journal.pone.0135989.g001

consumption and medication use were recorded. Patients' weight and height were also recorded, and used to calculate BMI $\left(\mathrm{kg} / \mathrm{m}^{2}\right)$ values.

Patients with the following conditions, which are known to interfere with or lead to the misinterpretation of $\mathrm{HbAlc}$ results, were excluded from participation: anemia, chronic renal disease and/or presence of hemoglobin variants [17].

After an overnight fast, blood samples were drawn to determine HbAlc levels, blood cell counts, lipid profile, creatinine and glucose concentrations. The OGTT was performed according to current recommendations [1,9]. Plasma glucose and serum lipid levels were determined by enzymatic methods, and creatinine concentrations were estimated by the Jaffe reaction (Modular P, Roche Diagnostics, Basel, Switzerland). Hemograms were performed by flow cytometry (ABX Pentra DX 120, HORIBA, Kyoto, Japan). HbAlc levels were determined by a HPLC method (Variant II Turbo HbA1c, BioRad Laboratories, Hercules, CA, USA). This method is a National Glycohemoglobin Standardization Program (NGSP) certified method (http://www.ngsp.org/prog/index.html), and is aligned with International Federation of Clinical Chemistry (IFCC) reference method. The Clinical Pathology department of the HCPA is a 
participant of the HbA1c External Quality Assurance Program, in which it has shown adequate peformance. GDM was diagnosed according to WHO 1999 criteria (FG $\geq 7.0 \mathrm{mmol} / \mathrm{L}$ and $2 \mathrm{~h}$ $\geq 7.7 \mathrm{mmol} / \mathrm{L}$ ); after June 2011, we also included patients diagnosed through ADA/WHO 2013 criteria (one out of three of the following cut-off points: fasting glycemia $\geq 5.1 \mathrm{mmol} / \mathrm{L}, 1 \mathrm{~h}$ $\geq 10.0 \mathrm{mmol} / \mathrm{L}$ and $2 \mathrm{~h} \geq 8.5 \mathrm{mmol} / \mathrm{L}$ ) [1,9,18]. The final diagnosis according to either WHO1999 or ADA/WHO 2013 criteria was considered for data description and summarization purposes.

The present study was approved by the Research Ethics Committee of the Hospital de Clínicas de Porto Alegre (HCPA), under protocol number 10-0475.

\section{Statistical analyses}

Data were expressed as mean and SD for normally distributed variables, and as median (range) for non-Gaussian variables. Student's T-tests, Mann-Whitney $U$ tests, McNemar tests and kappa coefficients were used as appropriate. Receiver Operating Characteristic (ROC) curve was used to analyze the performance of the $\mathrm{HbAlc}$ test in diagnosing GDM considering the OGTT as reference diagnostic criteria. For this analysis, we initially considered patients diagnosed according to WHO $1999(\mathrm{~N}=262)$ and ADA/WHO 2013 criteria $(\mathrm{N}=145)$ separately. An analysis was then performed including patients diagnosed according to both criteria. A ROC statistics based upon logistic regression analysis considering the covariates "previous history of GDM", "age" and "BMI" in the model were also carried out. Sensitivity, specificity and likelihood ratios (LR) for different HbAlc cut-off points were calculated. LR greater than 1 for a positive test is associated with the presence of the disease (LR+), while LR lower than 1 for a negative test is associated with the absence of the disease (LR-) [19]. To increase the clinical applicability of the present results, we also estimated the post-test probability of GDM using the Fagan nomogram [20] considering a pre-test probability of $10 \%$, which corresponds to the mean worldwide prevalence of GDM [21]. A significance level of 5\% was adopted for all tests, and the IBM SPSS software for Windows, version 19.0 (Statistical Package for Social SciencesProfessional Statistics, IBM Corp., Armonk, USA) was used for all statistical analyses, except for ROC curves comparison where the R-project/pROC was used.

\section{Results}

Of the 283 pregnant women recruited, 21 were excluded ( 1 renal disease, 9 anemia, 10 no blood sample available and 1 OGTT incomplete) and 262 were included in the study, and were assessed as to the presence or absence of GDM according to WHO 1999 criterion. A total of 145 of these patients were also classified with or without GDM according to ADA/WHO 2013 criteria. All patients were in the third trimester of pregnancy (gestational age $=27 \pm 5$ weeks) and presented ages between 23 and 35 years. The clinical and laboratory characteristics of study participants are depicted in Table 1.

A total of 86 women (33\%) presented with GDM, of whom 72 were diagnosed by WHO 1999 criteria. Twenty-six of these women were also diagnosed according to ADA/WHO 2013 criteria, while 14 patients were only diagnosed by ADA/WHO 2013 criteria. The WHO 1999 and ADA/WHO 2013 criteria $(\mathrm{N}=142)$ showed good diagnostic agreement (kappa = 0.639; $\mathrm{p}<0.001)$.

There was a statistically significant difference in the age, BMI, blood pressure and history of GDM between women with and without GDM $(\mathrm{P}<0.001)$. HbAlc values were $37 \pm 5 \mathrm{mmol} / \mathrm{mol}$ $(5.5 \pm 0.5 \%)$ and $32 \pm 4 \mathrm{mmol} / \mathrm{mol}(5.1 \pm 0.4 \%)$ for pregnant women with and without GDM, respectively $(\mathrm{P}<0.001)$. 
Table 1. Clinical and laboratory characteristics of pregnant women with and without GDM, according to WHO 1999 or ADA/WHO $2013^{\mathrm{a}}$ diagnostic criteria.

\begin{tabular}{|c|c|c|c|}
\hline & \multicolumn{2}{|c|}{ WHO 1999 and/or ADA/WHO 2013 OGTT } & \multirow[b]{3}{*}{$\boldsymbol{P}$} \\
\hline & - GDM & + GDM & \\
\hline & $N=176$ & $\mathrm{~N}=86$ & \\
\hline Age (years) & $28 \pm 6.3$ & $32 \pm 5.7$ & $<0.001$ \\
\hline Gestational Age (weeks) & $27 \pm 5.1$ & $26 \pm 5.5$ & 0.152 \\
\hline BMI (kg/m2) & $29 \pm 6.4$ & $32 \pm 5.4$ & $<0.001$ \\
\hline SBP $(\mathrm{mmHg})$ & $111 \pm 12.6$ & $117 \pm 14.8$ & $<0.001$ \\
\hline DBP (mmHg) & $66 \pm 9.6$ & $74 \pm 10.5$ & $<0.001$ \\
\hline FG (mmol/L) & $4.5 \pm 0.4$ & $5.2 \pm 0.9$ & NA \\
\hline $1 \mathrm{hG}(\mathrm{mmol} / \mathrm{L})^{\mathrm{a}}$ & $6.7 \pm 1.4$ & $9.6 \pm 1.7$ & NA \\
\hline 2hG (mmol/L) & $6.0 \pm 1.0$ & $8.8 \pm 1.8$ & NA \\
\hline HbA1c [mmol/mol (\%)] & $32 \pm 4(5.1 \pm 0.4)$ & $37 \pm 5(5.5 \pm 0.5)$ & $<0.001$ \\
\hline $\mathrm{Hb}(\mathrm{g} / \mathrm{dL})$ & $12 \pm 0.8$ & $12 \pm 0.8$ & $>0.500$ \\
\hline Cholesterol (mg/dL) & $212( \pm 40,5)$ & $229( \pm 53,5)$ & 0.2510 \\
\hline HDLCholesterol (mg/dL) & $51( \pm 13,3)$ & $59( \pm 16,9)$ & $<0.001$ \\
\hline FHDM (\%) & 59.5 & 66.0 & 0.419 \\
\hline PHGDM (\%) & 4.5 & 11.8 & $<0.01$ \\
\hline PHHT (\%) & 19.4 & 20.6 & 0.832 \\
\hline
\end{tabular}

a After June 2011.

Data are mean $\pm \mathrm{SD}$, except for FHDM, PHGDM and PHHT. GDM = gestational diabetes mellitus, OGTT = oral glucose tolerance test, $\mathrm{BMI}=$ body mass index, $\mathrm{SBP}=$ systolic blood pressure, $\mathrm{DBP}=$ diastolic blood pressure, $\mathrm{FG}=$ fasting glycemia, $1 \mathrm{hG}=$ glycemia after $1 \mathrm{~h}$ of glucose load, $2 \mathrm{hG}=$ glycemia $2 \mathrm{~h}$ after glucose load, $\mathrm{Hb}=$ haemoglobin, FHDM = family history of DM, PHDMG = previous history of GDM, PHHT = previous history of hypertension.

doi:10.1371/journal.pone.0135989.t001

A ROC analysis (Fig 2, Table 2) considering WHO 1999 criteria alone as the reference test found an AUC of 0.714 ( $\mathrm{p}<0.001$ ) and the cut-off point obtained by the point with the best equilibrium between sensitivity and specificity (100\%-to-100\% diagonal) was HbA1c value of $35 \mathrm{mmol} / \mathrm{mol}$ (5.3\%). This cut-off point presented sensitivity and specificity rates of $68.1 \%$ and 63.2\%, respectively. Similar results were obtained when ADA/WHO 2013 criteria alone were used as reference for the ROC analysis.

When both WHO 1999 and ADA/WHO 2013 criteria were considered, the AUC was 0.757 $(\mathrm{p}<0.001)$ and the cut-off points obtained were very similar to those obtained when each set of criteria were used separately. The ROC statistics based upon logistic regression analysis considering the covariates "previous history of GDM", "age" and "BMI" in the model showed an AUC slightly different but with no statistical difference (AUC adjusted $=0.787 ; \mathrm{p}>0,05$ ).

The LR+ and LR-were also calculated for the HbA1c values obtained (Table 2). HbA1c values of $31 \mathrm{mmol} / \mathrm{mol}(5.0 \%)$ and $40 \mathrm{mmol} / \mathrm{mol}$ (5.8\%) were the first points in the ROC curve with sensitivity and specificity values over $90 \%$, respectively. $\mathrm{HbAlc} \geq 31 \mathrm{mmol} / \mathrm{mol}(5.0 \%)$ had a LR+ of 1.33 (95\% CI 1.17 to 1.51 ) and a LR-of 0.32 (95\% CI 0.17 to 0.61 ); conversely, $\mathrm{HbAlc} \geq 40 \mathrm{mmol} / \mathrm{mol}$ (5.8\%) exhibited a LR+ of 5.14 (95\% CI 2.49 to 10.63 ) and a LR-of 0.78 (95\% CI 0.68 to 0.88 ). Considering a pre-test probability of $10 \%$ for GDM, the post-test probabilities for GDM were approximately $3.5 \%$ and $40 \%$ for $\mathrm{HbAlc} \leq 31 \mathrm{mmol} / \mathrm{mol}(5.0 \%)$ and $\mathrm{HbAlc} \geq 40 \mathrm{mmol} / \mathrm{mol}$ (5.8\%), respectively (Fig 3).

Based on these data, and considering HbAlc $\geq 40 \mathrm{mmol} / \mathrm{mol}$ (5.8\%) as rule in cut-off point for GDM, 32 pregnant women were classified with GDM. These women were more likely to report previous GDM and a family history of DM, tended to be older, and to have higher BMI 


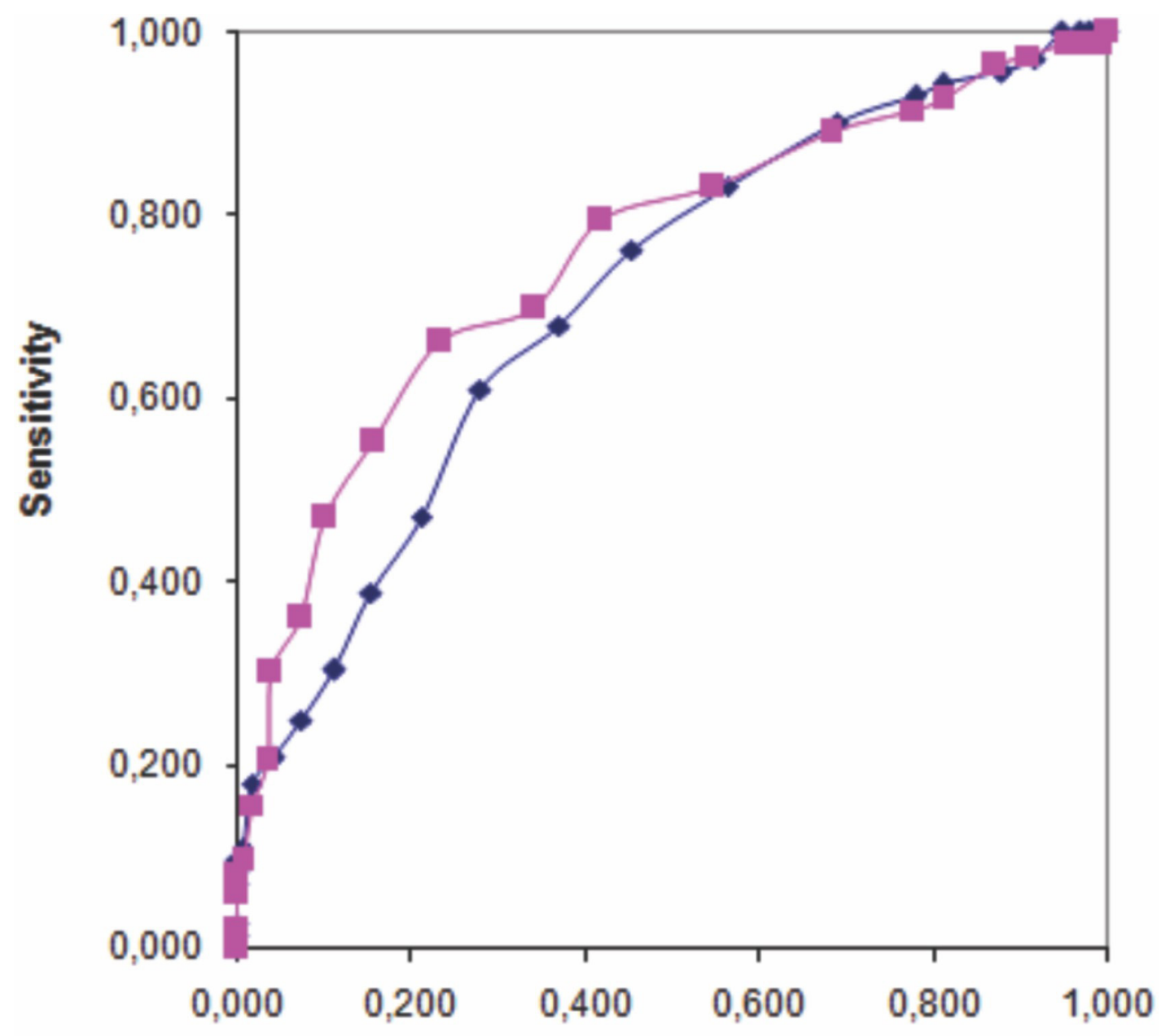

\section{1-Specificity}

Fig 2. ROC curve for HbA1c values in diagnosing GDM. Blue Line-HbA1c vs WHO $1999 \mathrm{~N}=262$, Red line-HbA1c vs $A D A / W H O 2013 * \mathrm{~N}=142$. * After June 2011.

doi:10.1371/journal.pone.0135989.g002

values, blood pressure (systolic and diastolic), glycemia (fasting, $1 \mathrm{~h}$ and $2 \mathrm{hG}$ ) and cholesterol levels. Five of these women presented with $\mathrm{HbAlc} \geq 48 \mathrm{mmol} / \mathrm{mol}(6.5 \%)$.

The agreement between the diagnoses provided according to the HbAlc cut-off adopted in this study and the OGTT results was fair (kappa $=0.253$; $\mathrm{p}<0.001$ ). Of the 72 women classified as having GDM according to WHO 1999 criteria, 18 had $\mathrm{HbAlc} \geq 40 \mathrm{mmol} / \mathrm{mol}$ (5.8\%). Based on ADA/WHO 2013 criteria, 40 patients were classified with GDM. Ten of these had HbA1c $\geq 40 \mathrm{mmol} / \mathrm{mol}$ (5.8\%). Of the 26 pregnant women diagnosed as being positive for GDM by both WHO 1999 and ADA/WHO 2013 criteria, 5 had HbAlc $\geq 40 \mathrm{mmol} / \mathrm{mol}$ (5.8\%). The proportion of women classified as positive and negative for the condition by OGTT results and the HbA1c cut-off adopted in this study differed significantly $(\mathrm{p}<0.001)$. 
Table 2. HbA1c test performance in diagnosing GDM.

\begin{tabular}{|c|c|c|c|c|}
\hline HbA1c [mmol/mol (\%)] & Sensitivity (\%) & Specificity (\%) & $\operatorname{LR}+(95 \% \mathrm{Cl})$ & LR-(95\% Cl) \\
\hline $31(5.0)$ & 89.7 & 32.6 & $1.33(1.17-1.51)$ & $0.32(0.17-0.61)$ \\
\hline $32(5.1)$ & 83.9 & 44.3 & $1.56(1.32-1.84)$ & $0.36(0.21-0.58)$ \\
\hline $33(5.2)$ & 78.2 & 58.3 & $1.87(1.52-2.31)$ & $0.37(0.25-0.57)$ \\
\hline $34(5.3)$ & 70.1 & 66.9 & $2.12(1.65-2.72)$ & $0.45(0.32-0.63)$ \\
\hline $36(5.4)$ & 63.2 & 76.0 & 2.63 (1.93-3.59) & $0.48(0.36-0.65)$ \\
\hline $37(5.5)$ & 50.6 & 82.9 & $2.95(2.00-4.34)$ & $0.60(0.48-0.75)$ \\
\hline $38(5.6)$ & 41.4 & 88.0 & $3.45(2.15-5.53)$ & $0.67(0.55-0.80)$ \\
\hline $39(5.7)$ & 31.0 & 90.9 & $3.39(1.93-5.96)$ & $0.76(0.65-0.88)$ \\
\hline $40(5.8)$ & 26.4 & 94.9 & $5.14(2.49-10.63)$ & $0.78(0.68-0.88)$ \\
\hline $41(5.9)$ & 20.7 & 97.1 & 7.24 (2.78-18.85) & $0.82(0.73-0.91)$ \\
\hline $42(6.0)$ & 15.0 & 98.3 & $8.72(2.55-29.79)$ & $0.79(0.79-0.95)$ \\
\hline \multicolumn{3}{|c|}{ AUC } & \multicolumn{2}{|c|}{0.757} \\
\hline
\end{tabular}

$\mathrm{LR}+=$ positive likelihood ratio; LR- = negative likelihood ratio. $\mathrm{N}=262, \mathrm{WHO} 1999$ and/or ADA/WHO 2013 reference criteria.

doi:10.1371/journal.pone.0135989.t002

\section{Discussion}

In this study, we evaluated the performance of $\mathrm{HbAlc}$ test to detect GDM in comparison to a traditional OGTT. Our data showed, as expected, that $\mathrm{HbA1c}$ values in pregnant women without GDM were significantly lower than those found in pregnant women with GDM. However, there was some overlap between the HbAlc values displayed by participants in the two groups. These findings are in agreement with other studies, which found mean $\mathrm{HbAlc}$ values of 30 to $37 \mathrm{mmol} / \mathrm{mol}$ (4.9 to 5.5\%) in pregnant women without GDM [22-26]. The presence of anaemia can cause a reduction in $\mathrm{HbAlc}$ values, and some studies suggest that this may be one of the reasons for the lower HbA1c levels observed during pregnancy [24]. In our study, anaemia could not explain these differences, since women with and without GDM presented with similar levels of total haemoglobin, within the normal range. We believe that such differences in $\mathrm{HbAlc}$ values are more likely to be caused by other physiological processes which take place during pregnancy [25].

The ROC curve analysis used to evaluate the performance of HbA1c test in diagnosing GDM displayed similar AUC values for the WHO 1999 and ADA/WHO 2013 reference criteria (0.714 and 0.756, respectively), indicating an absence of differences in HbA1c performance against the OGTT, regardless of the criteria used to diagnose GDM.

The HbAlc cut-off points of $35 \mathrm{mmol} / \mathrm{mol}(5.3 \%)$ and $36 \mathrm{mmol} / \mathrm{mol}(5.4 \%)$ presented the best equilibrium between sensitivity and specificity when WHO 1999 and ADA/WHO 2013 criteria were used, respectively. However, the sensitivity values for these cut-points were not high enough to allow ruling out GDM diagnoses (68\% and 70\% for the WHO 1999 and ADA/ WHO 2013 criteria, respectively). On the other hand, the use of $\mathrm{HbAlc} \geq 40 \mathrm{mmol} / \mathrm{mol}$ (5.8\%) as a cut-point presented excellent specificity in ruling in GDM (93\% and 95\% for WHO 1999 and ADA/WHO 2013 criteria, respectively). A previous study suggested the use of HbA1c $\geq 42 \mathrm{mmol} / \mathrm{mol}$ (5.95\%) as a cut-off point to confirm the diagnosis of GDM in women in India (28.6\% and $97.2 \%$ for sensitivity and specificity, respectively) [24].

When we used the $\mathrm{HbAlc} \geq 40 \mathrm{mmol} / \mathrm{mol}$ (5.8\%) cut-off point to detect participants with and without GDM, it was found that those classified as having the condition were more likely to be older and to have had previous GDM and a family history of DM, as well as higher BMI, blood pressure (systolic and diastolic), glycemia (fasting, $1 \mathrm{~h}$ and $2 \mathrm{hG}$ ) and cholesterol levels. 


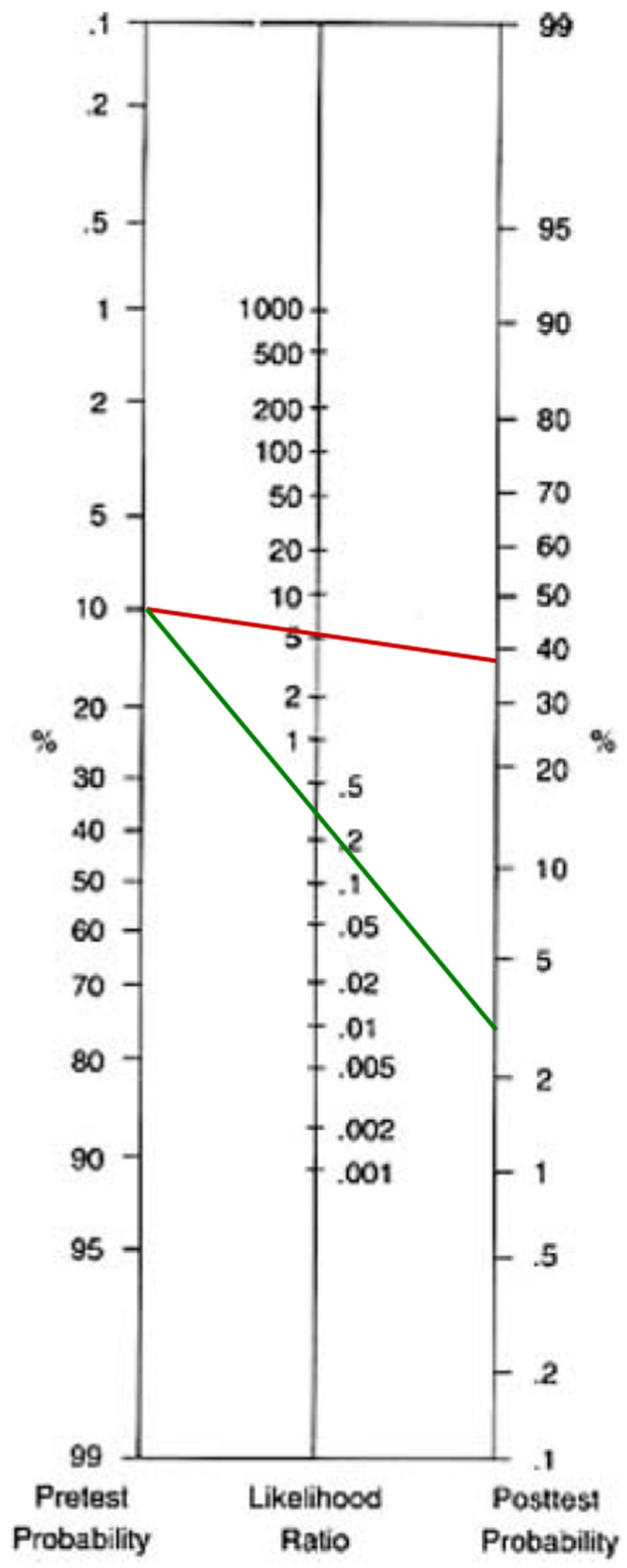

Fig 3. Fagan's Nomogram for the HbA1c test showing post-test probabilities of gestational diabetes in pregnant women with $\mathrm{HbA1c} \leq \mathbf{3 1} \mathrm{mmol} / \mathrm{mol}$ (5.0\%) and $\mathrm{HbA} 1 \mathrm{c} \geq \mathbf{4 0} \mathrm{mmol} / \mathrm{mol}(5.8 \%)$.

doi:10.1371/journal.pone.0135989.g003 
These characteristics have been found to be related to an increased probability of adverse outcomes for both the mother and the babies $[2,3]$.

As has been previously reported in diagnostic studies of type 2 DM [11-13], the HbAlc test seems to identify a different GDM group from that diagnosed by glucose-based tests. This fact is corroborated by the poor diagnostic agreement between tests.

Our results showed that $38 \%$ of GDM cases were diagnosed by the cut-off point of $\mathrm{HbAlc}$ $\geq 40 \mathrm{mmol} / \mathrm{mol}(5.8 \%)$, and that $5 \%$ of pregnant women classified as GDM-negative by the OGTT would have been diagnosed as having the condition according to the HbAlc test. The use of the HbAlc test as a diagnostic criterion in this group would identify 9 women with GDM who would not have been identified by the OGTT alone. In agreement with our results, a recent Australian study showed that a subgroup of pregnant women have a normal OGTT but elevated $\mathrm{HbAlc}$, suggesting that $\mathrm{HbAlc}>40 \mathrm{mmol} / \mathrm{mol}(5.8 \%)$ during pregnancy is a clinically relevant finding [27].

The positive and negative likelihood ratios suggested that a woman with GDM is about five times more likely to have $\mathrm{HbAlc}$ levels $\geq 40 \mathrm{mmol} / \mathrm{mol}(5.8 \%)$ than a woman without the condition. On the other hand, a GDM-negative woman is about three times more likely to have HbAlc concentrations $\leq 31 \mathrm{mmol} / \mathrm{mol}(5.0 \%)$ than a woman with the disease. The LR+ and LRwere very significant for both HbAlc cut-off points analysed [19,28]. Also, by using Bayes theorem rationale, the post-test probability for GDM was $3.4 \%$ for the $\mathrm{HbAlc} \leq 31 \mathrm{mmol} / \mathrm{mol}$ (5.0\%) cut-point, which is much lower than the pre-test probability of $10 \%$, and $40 \%$ for $\mathrm{HbAlc}$ $\geq 40 \mathrm{mmol} / \mathrm{mol}$ (5.8\%), showing a four-fold increase from the pre-test probability [20,28].

The present study did have a few limitations. Firstly, it was a cross-sectional study and the relationship between $\mathrm{HbAlc}$ and maternal and/or fetal adverse outcomes could not be analysed. Secondly, our sample of Brazilian pregnant women may differ from other populations, although our results are in accordance with those of other studies which involved different samples [22,26,27]. Third, some limitations are associated with the HbAlc test itself, as its applicability will depend on the observance of all factors affecting HbAlc results. Finally, we did not carry out any cost effectiveness analyses, and the HbAlc is known to be more expensive than glucose-based tests. However, it is possible that the advantages of the HbAlc test may outweigh its disadvantages.

Clinicians should be aware that all diagnostic tests have some limitations and may not always be effective. Although the HbAlc test does not have sufficient sensitivity and specificity to be used as the only diagnostic test for GDM, the use of different HbAlc cut-off points in combination with the OGTT could be useful in detecting the condition, as has also been suggested by other studies in the literature $[26,29]$. HbA1c test has several advantages over OGTT, including less biological variation, higher reproducibility, better sample stability and no need of fasting.

In conclusion, different HbAlc cut-off points, in combination with OGTT, may be a useful diagnostic tool for GDM.

\section{Acknowledgments}

We thank Dr Angela Jacob Reichelt for her careful review of this manuscript. Parts of this study were presented as an Oral Communication at the 20th IFCC-EFLM European Congress of Clinical Chemistry and Laboratory-Euromedlab, Milan, Italy, $19^{\text {th }}-23^{\text {rd }}$ May, 2013. 


\section{Author Contributions}

Conceived and designed the experiments: PBR JLC. Performed the experiments: PBR GC LSW. Analyzed the data: PBR SPS JLC. Contributed reagents/materials/analysis tools: PBR GC LSW. Wrote the paper: PBR SPS JLC.

\section{References}

1. World Health Organization. Definition, diagnosis and classification of diabetes mellitus and its complications: Report of a WHO consultation. Part 1: Diagnosis and Classification of Diabetes Mellitus. WHO/ NCD/NCS/99 2 ed, Geneva 1999.

2. Suhonem L, Hiilesmaa V, Teramo K. Glycemic control during early pregnancy and fetal malformations in women with type 1 diabetes mellitus. Diabetologia 2000; 43:79-82. PMID: 10663219

3. Metzger BE, Lowe LP, Dyer AR, Trimble ER, Chaovarindr U, Coustan DR et al. Hyperglycemia and adverse pregnancy outcomes. N Engl J Med 2008; 358:1991-2002. doi: 10.1056/NEJMoa0707943 PMID: 18463375

4. Falavigna M, Schmidt MI, Trujillo J, Alves LF, Wendland ER, Torloni MR et al. Effectiveness of gestational diabetes treatment: a systematic review with quality of evidence assessment. Diabetes Res Clin Pract 2012; 98:396-405. doi: 10.1016/j.diabres.2012.09.002 PMID: 23031412

5. Hartling L, Dryden DM, Guthrie A, Muise M, Vandermeer B, Donovan L. Benefits and harms of treating gestational diabetes mellitus: a systematic review and meta-analysis for the U.S. Preventive Services Task Force and the National Institutes of Health Office of Medical Applications of Research. Ann Intern Med 2013; 159:123-129. doi: 10.7326/0003-4819-159-2-201307160-00661 PMID: 23712381

6. Waugh N, Pearson D, Royle P. Screening for hyperglycaemia in pregnancy: Consensus and controversy. Best Pract Res Clin Endocrinol Metab 2010; 24:553-571. doi: 10.1016/j.beem.2010.06.004 PMID: 20832736

7. Buckley BS, Harreiter J, Damm P, Corcoy R, Chico A, Simmons D et al. Gestational diabetes mellitus in Europe: Prevalence, current screening practice and barriers to screening. A review. Diabet Med 2012; 29:844-854. doi: 10.1111/j.1464-5491.2011.03541.x PMID: 22150506

8. Farrar D, Duley L, Medley N, Lawlor DA. Different strategies for diagnosing gestational diabetes to improve maternal and infant health. Cochrane Database Syst Rev. 2015 Jan 21; 1:CD007122. doi: 10. 1002/14651858.CD007122.pub3

9. American Diabetes Association. Classification and diagnosis of Diabetes. Diabetes Care 2015; 38 (suppl.1):s8-s16.

10. World Health Organization. Use of glycated haemoglobin (HbA1c) in the diagnosis of diabetes mellitus. Abbreviated report of a WHO consultation 2011. Available: http://www.who.int/diabetes/publications/ diagnosis_diabetes2011/en/index.html. Accessed 5 October 2014.

11. Cavagnolli G, Comerlato J, Comerlato C, Renz PB, Gross JL, Camargo JL. HbA1c measurement for the diagnosis of diabetes: is it enough? Diabet Med 2011; 28:31-35. PMID: 21210540

12. Kramer CK, Araneta MR, Barrett-Connor E. HbA1c and diabetes diagnosis: The Rancho Bernardo Study. Diabetes Care 2010; 33:101-103. doi: 10.2337/dc09-1366 PMID: 19837792

13. Carson AP, Reynolds K, Fonseca VA, Munter P. Comparison of HbA1c and fasting glucose criteria to diagnose diabetes among U.S. adults. Diabetes Care 2010; 33:95-97. doi: 10.2337/dc09-1227 PMID: 19808920

14. Lowe LP, Metzger BE, Dyer AR, Lowe J, McCance DR, Lappin TR et al. Hyperglycemia and adverse pregnancy outcomes (HAPO) study associations of maternal HbA1c and glucose with pregnancy outcomes. Diabetes Care 2012; 35:574-580. doi: 10.2337/dc11-1687 PMID: 22301123

15. Sacks DB. HbA1c versus glucose testing: a comparison. Diabetes Care 2011; 34:518-523. doi: 10 . 2337/dc10-1546 PMID: 21270207

16. Bossuyt PM, Reitsma JB, Bruns DE, Gatsonis CA, Glasziou PP, Irwig LM et al. Towards complete and accurate reporting of studies of diagnostic accuracy: The STARD initiative. BMJ 2003; 326:41-44. PMID: 12511463

17. Sacks DB, Arnold M, Bakris GL, Bruns DE, Horvath AR, Kirkman MS et al. Guidelines and Recommendations for Laboratory Analysis in the Diagnosis and Management of Diabetes Mellitus. Clin Chem 2011; 57:e1-e47. doi: 10.1373/clinchem.2010.161596 PMID: 21617152

18. World Health Organization. Diagnostic Criteria and Classification of Hyperglycaemia First Detected in Pregnancy. WHO Guidelines 2013. Available: http://www. who.int/diabetes/publications/ Hyperglycaemia_In_Pregnancy/en/index.html. Accessed 10 December 2013.

19. Deeks JJ, Altman DG. Diagnostic tests 4: likelihood ratios. BMJ 2004; 329:168-169. PMID: 15258077 
20. Fagan TJ. Letter: normogram for Bayes theorem. N Engl J Med 1975; 293:257.

21. Wendland EM, Torloni MR, Falavigna M, Trujillo J, Dode MA, Campos MA et al. Gestational diabetes and pregnancy outcomes: a systematic review of the World Health Organization (WHO) and the International Association of Diabetes in Pregnancy Study Groups (IADPSG) diagnostic criteria. BMC Pregnancy Childbirth 2012; 12:23. doi: 10.1186/1471-2393-12-23 PMID: 22462760

22. Balaji V, Madhuri BS, Ashalatha S, Sheela S, Suresh S, Seshiah V. HbA1c in gestational diabetes mellitus in asian indian women. Diabetes Care 2007; 30:1865-1867. PMID: 17416790

23. Mosca A, Paleari R, Dalfra MG, Di Cianni G, Cuccuru I, Pellegrini G et al. Reference intervals for hemoglobin a(1c) in pregnant women: Data from an italian multicenter study. Clin Chem 2006; 52:11381143. PMID: 16601066

24. O' Connor COSP, Owens LA, Carmody L, Avalos G, Nestor L, Lydon K. Trimester-specific reference intervals for haemoglobin A 1c (HbA1c) in pregnancy. Clin Chem Lab Med 2012; 5:905-909.

25. Hiramatsu $Y$, Shimizu I, Omori $Y$, Nakabayashi M. Determination of reference intervals of glycated albumin and hemoglobin $\mathrm{HbA1c}$ in healthy pregnant japanese women and analysis of their time courses and influencing factors during pregnancy. Endocr J 2012; 59:145-151. PMID: 22166921

26. Rajput $R$, Yogesh $Y$, Rajput $M$, Nanda S. Utility of $\mathrm{HbA} 1 \mathrm{c}$ for diagnosis of gestational diabetes mellitus. Diabetes Res Clin Pract 2012; 98:104-107. doi: 10.1016/j.diabres.2012.02.018 PMID: 22456454

27. Rowan JA, Budden A, Sadler LC. Women with a nondiagnostic $75 \mathrm{~g}$ glucose tolerance test but elevated $\mathrm{HbA1C}$ in pregnancy: An additional group of women with gestational diabetes. Aust N Z J Obstet Gynaecol 2014; 54(2): 177-180. doi: 10.1111/ajo.12166 PMID: 24359339

28. Akobeng AK. Understanding diagnostic tests 2 : likelihood ratios, pre- and post-test probabilities and their use in clinical practice. Acta Paediatr 2007; 96:487-491. PMID: 17306009

29. Donovan L, Hartling L, Muise M, Guthrie A, Vandermeer B, Dryden DM. Screening Tests for Gestational Diabetes: A Systematic Review for the US Preventive Services Task Force. Ann Intern Med 2013; 159(2):115-122. doi: 10.7326/0003-4819-159-2-201307160-00657 PMID: 23712349 